\title{
Infecção por Rhodococcus em doente imunocompetente - a propósito de um caso
}

\author{
Rhodococcus infection in immunocompetent patient - a case report
}

\author{
Susana Barbosa, Paula Felgueiras, Diana Guerra, Alfredo Pinto \\ Serviço de Medicina'. Hospital de Santa Luzia, Unidade Local de Saúde do Alto Minho.
}

\begin{abstract}
Resumo
0 Rhodococcus equi raramente causa infecção no humano, sendo que a maioria dos casos descritos estão associados a doentes imunodeprimidos. Os autores apresentam o caso de um homem de 65 anos que foi admitido no serviço de urgência por agravamento da dispneia habitual, tosse e febre. Foi internado com o diagnóstico de sépsis com ponto de partida respiratório em pneumonia de focos múltiplos e peritonite. Medicado empiricamente com ceftriaxone, com melhoria clínica. Isolamento no líquido ascítico de Rhodococcus spp. Cumpriu 2 meses de antibioterapia com doxiciclina, com boa evolução clínica, analítica e radiológica. Os autores apresentam este caso dada a raridade da situação e pretendem realçar a necessidade de um elevado índice de suspeição para o diagnóstico da infecção por este agente em doentes imunocompetentes.
\end{abstract}

Palabras clave: Rhodococcus. Doente imunocompetente. Infecção pulmonar

\section{Introdução}

A doença humana por Rhodococcus equi (anteriormente conhecido por Corynebacterium equi) foi pela primeira vez descrita em 1967. ${ }^{1}$ Até aos anos 80 foram publicados uma dezena de casos e desde então assistiu-se a um claro aumento do número sobretudo associado à infecção pelo vírus da imunodeficiência humana (VIH) ${ }^{2-5}$ Trata-se de um cocobacilo pleomórfico, gram-positivo, aeróbio, intracelular facultativo e parcialmente álcool-ácido resistente. ${ }^{2-4} \mathrm{~A}$ incidência é maior no género masculino $(3: 1)$ e na $3^{\text {a }}$ e $4^{\text {a }}$ décadas de vida. ${ }^{4-6}$ Os locais mais frequentes de isolamento são: pulmão, sangue, sistema nervoso central, pele e articulações. ${ }^{5}$ Esta bactéria tem um perfil variável de sensibilidade aos antimicrobianos e o tratamento exige antibioterapia prolongada. ${ }^{3-5}$

\section{Caso clínico}

Sexo masculino, 66 anos. Admitido no Serviço de Urgência por agravamento da dispneia habitual, associada a tosse e febre com 2 dias de evolução. Doente com história clínica de cardiomiopatia de etiologia valvular e isquémica com depressão severa da função sistólica do ventrículo esquerdo e insuficiência cardíaca em classe II-III de New York Heart Association e adenocarcinoma do pulmão em 2002 submetido a lobectomia e radioterapia, sem evidência de recidiva até à data.

Na admissão no Serviço de Urgência estava prostrado, com FR 20cpm em repouso, TA- 115/60mmHg, FC- 75bpm. Auscultação cardíaca: rítmica; sons de prótese. Auscultação pulmonar: crepitações inspiratórias na base direita e diminuição dos sons no 1/3 inferior do hemitórax esquerdo. Abdómen: globoso, mole, depressivel com sinais de ascite. Edemas bimaleolares.

\begin{abstract}
Rhodococcus equi rarely causes human infection, and most of the described cases are associated with immunosuppressed patients. The authors present a 65-year-old man who was admitted to the emergency department with worsening of dyspnea, cough and fever. He was admitted with a diagnosis of sepsis with respiratory starting point in multiple foci pneumonia and peritonitis. He was medicated empirically with ceftriaxone, with clinical improvement. Isolation in the ascites fluid of Rhodococcus spp. He completed two months of antibiotic treatment with doxycycline, with clinical, analytical and radiological improvement. The authors present this case due to the rarity of the situation and highlight the need for a high index of suspicion for the infection diagnosis by this agent in immunocompetent patients.
\end{abstract}

Key words: Rhodococcus. Immunocompetent patient. Pulmonary infection

Dos exames complementares de diagnóstico realizados: gasimetria arterial com insuficiência respiratória hipoxémica (ph 7.4, p02 66mmHg, pC02 39mmHg); análises: Hb 10.4g/dL, anemia normocítica e normocrómica, leucocitose com neutrofilia (12.50 x 10^9/L), proteína C reactiva $7.6 \mathrm{mg} / \mathrm{dL}$, ureia $42 \mathrm{mg} / \mathrm{dl}$, creatinina 0,99mg/dl, AST 17UI/L, ALT 6UI/L, FA 143UI/L, GGT 158UI/L, BNP 2843pg/mL, LDH 250Ul/L, proteínas totais $5.4 \mathrm{~g} / \mathrm{dL}$, albumina $3.6 \mathrm{~g} / \mathrm{dL}$. Radiografia de tórax (figura 1): infiltrados pulmonares bilaterais com hipotransparência dos 2/3 inferiores do hemitórax esquerdo compatível com derrame. Realizada toracocentese diagnóstica, com saída de líquido amarelo citrino: células $4064 \mathrm{~mm} \wedge 3$, eritrócitos $3500 \mathrm{~mm} \wedge 3$, leucócitos $564 \mathrm{~mm} \wedge 3$ com predomínio de

Figura 1. Radiografia de tórax: infiltrados pulmonares bilaterais com hipotransparência dos 2/3 inferiores do hemitórax esquerdo compatível com derrame

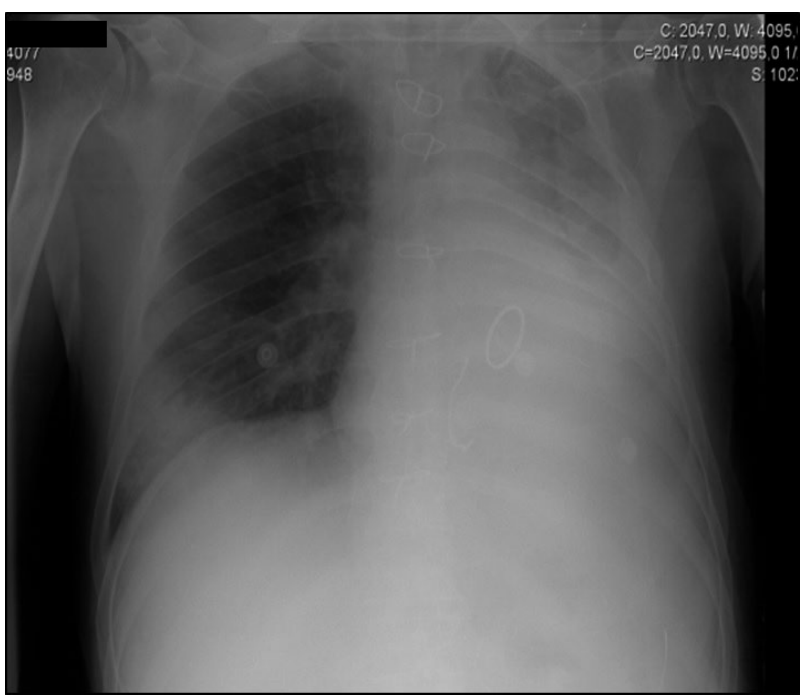


células mononucleadas (64\%), LDH 112UI/L, proteínas 4,4g/dL. Ecografia abdominal: fígado de dimensões normais, globoso, sem dilatação das vias biliares e baço de dimensões normais; ascite de médio volume, sem evidência de implantes peritoneais ou massas. Realizada paracentese diagnóstica com saída de líquido turvo: céIulas $4010 \mathrm{~mm} \wedge 3$, eritrócitos $3400 \mathrm{~mm} \wedge 3$, leucócitos $610 \mathrm{~mm} \wedge 3$ com 51\% de neutrófilos, albumina 2,6g/dL, LDH 116U//L. Gradiente sero-ascítico da albumina $<1,1 \mathrm{~g} / \mathrm{dL}$. Diagnosticada sépsis com ponto de partida em pneumonia de focos múltiplos, ascite com peritonite e insuficiência cardíaca descompensada. Foram colhidas hemoculturas e foi iniciado empiricamente ceftriaxone $2 \mathrm{~g} /$ dia que cumpriu durante 12 dias. Verificada melhoria clínica franca, com apirexia sustentada, descida dos parâmetros de infecção e regressão da ascite e do derrame pleural. Hemoculturas e exame bacteriológico de líquido pleural negativos e isolamento no exame bacteriológico do líquido ascítico de Rhodococcus spp. Serologias víricas para VIH, hepatite B e C negativas e imunoglobulinas séricas normais. Teve alta medicado com doxiciclina 100mg a cada $12 \mathrm{~h}$ durante 2 meses, com regressão da ascite e do derrame pleural.

\section{Discussão}

A infecção humana por Rhodoccoccus equi é rara. 0 Rhodococcus existe de uma forma ubiquitária no solo, sendo a principal via de transmissão a ingestão de partículas contaminadas e a inalação de aerossóis. ${ }^{3} 0$ local mais frequentemente afectado é o pulmão, ocorrendo pneumonia em 76\% dos casos e infecção extra-pulmonar em simultâneo em $18 \% .^{5}$

0 Rhodococcus tem um perfil variável de sensibilidade aos antibióticos, sendo geralmente sensíveis aos macrólidos, rifampicina, quinolonas, aminoglicosídeos, vancomicina e imipenem. ${ }^{5}$ Não está estabelecida uma terapêutica standard, mas a maioria dos autores defende que nos imunodeprimidos devem ser associados, pelo menos, 2 antibióticos com boa penetração intra-celular e nos imunocompetentes em geral será suficiente um antibiótico. ${ }^{5}$ A terapêutica antibiótica deve ser prolongada por um período igual ou superior a 2 meses, podendo ir até 6 meses nos imunodeprimidos., 0 prognóstico da infecção é pior nos doentes imunodeprimidos, sendo descrita uma taxa de mortalidade nos imunocompetentes de $11 \%{ }^{3}$

No caso apresentado, foi assumido que a ascite era secundária à anasarca e que houve disseminação do Rhodococcus a partir da pneumonia para o líquido ascítico. Verificouse resposta clínica ao ceftriaxone instituído empiricamente e desaparecimento do derrame pleural e da ascite com a doxicilina que cumpriu durante 2 meses.

Os autores apresentam este caso dada a raridade da situação, bem como para realçar a necessidade de um elevado índice de suspeição para o diagnóstico de infeções por agentes pouco comuns em doentes não imunodeprimidos.

\section{Bibliografia}

1. Golub B, Flak G, Spink W. Lung abscess due to Corynebacterium equi. Report of first human infection. Ann Intern Med 1967;66: 1174.

2. Severo L, Ritter P, Petrillo V, Dias C, Porto N. Infecção pulmonar por "Rhodococcus equi": relato dos dois primeiros casos brasileiros. J Pneumol 2001;27(3): 158-162.

3. Nunes S, Coutinho D, Cunha I, Moreira R. Infecção disseminada por Rhodococcus em doente imunossuprimida. Galicia Clin 2014;75(4): 188-190.

4. Faria J, Simões J, Eiras E, Furtado A. Infecção pulmonar por rhodococcus equi em doente VIH+. A propósito de um caso. Galicia Clin 2013;74(1): 29-32.

5. Slater L. Clinical features, diagnosis, therapy and prevention of Rhodococcus equi

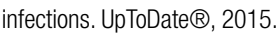

6. Esteves P, Mineiro A, Serrado M, Diniz A. Rhodococcus equi pneumonia in an HIV+ patient: an uncommon association. Rev Port Pneumol 2007;13(5): 703-9.

\section{Normas de publicación Galicia Clínica}

Galicia Clínica es la revista oficial de la Sociedad Gallega de Medicina Interna (SOGAMI). Se publican 4 números al año, simultáneamente en papel y en www.galiciaclinica info, incluyéndose en el segundo de ellos las comunicaciones enviadas a la correspondiente Reunión Ordinaria de la SOGAMI.

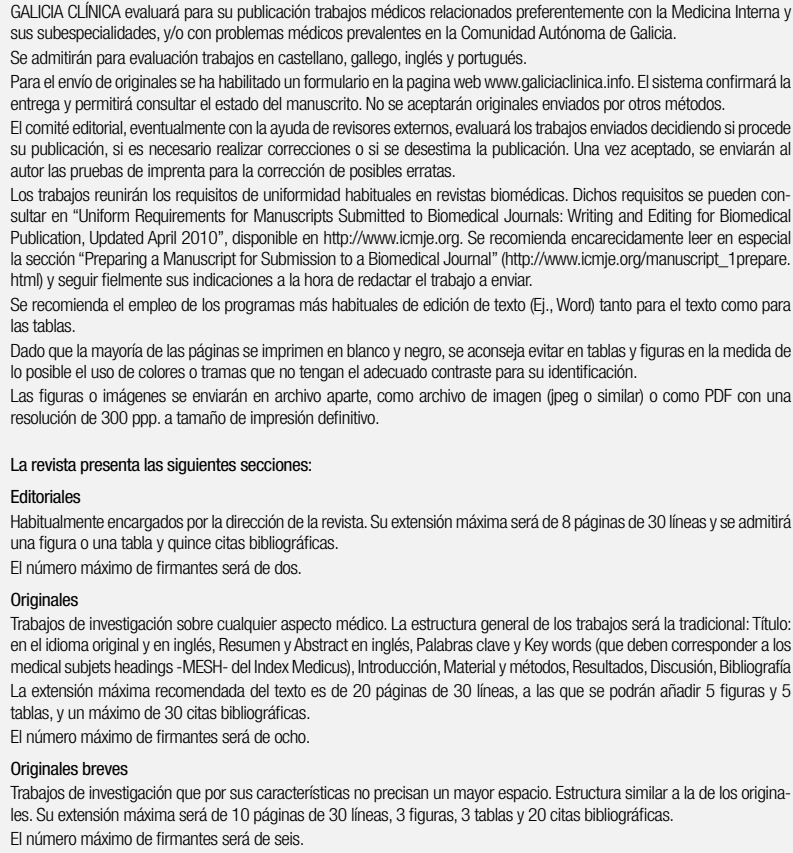

La dirección de la revista considerará para su publicación cualquier artículo relacionado con la medicina en cualquier aspecto, aunque no se incluya exactamente dentro de los supuestos anteriores. En este caso se recomienda antes de su envio contactar con la dirección para acordar las características del mismo. En el caso de que los trabajos enviados incluyan imágenes, figuras, tablas o textos sometidos a copyright, será responsabilidad de los autores la obtención de los permisos necesarios para su publicación. Todas las opiniones o afirmaciones expresadas en los artículos corresponden a los autores de los mismos. Tanto el comité editorial como la SOGAMI declinan cualquier responsabilidad a este respecto.

Los trabajos publicados serán propiedad de GALCIA CLÍNICA, cediendo los autores todos los derechos a la misma. 